\title{
PERSPECTIVE
}

\section{The sclera, the prion, and the ophthalmologist}

\section{J S Mehta, W A Franks}

Br J Ophthalmol 2002;86:587-592

Prions have emerged in the past 5 years as serious transmissible infective agents. Ocular tissue transplantation has come under scrutiny after potential infected tissue was transplanted into healthy patients. In this review we examine the evidence for the risk of transmission of prions after scleral transplantation and explore alternative materials that may be used in ocular surgery.

See end of article for authors' affiliations

...................

Correspondence to: Mr J S Mehta, Moorfields Eye Hospital, City Road, London ECIV 2PD, UK; jodmehta@hotmail.com

Accepted for publication 21 January 2002
$\mathrm{T}$ he past few years have seen the emergence of the prion as a serious transmissible infective agent. There are at present 106 confirmed deaths from variant Creutzfeldt-Jakob disease $(\mathrm{vCJD})^{1}$ (102 in the United Kingdom, three in France, and one in Republic of Ireland) in people who are believed to have contracted the disease by eating meat infected with bovine spongiform encephalopathy (BSE). In 1997 an incident occurred in which patients received ocular tissue from a donor who was eventually diagnosed as having CJD. The incident involved the donation of two corneas and both sclera to three patients. ${ }^{2}$ Postmortem pathology of the brain of the donor revealed a spongiform encephalopathy consistent with classic CJD. The risk of transmission of CJD, whether new variant or classic, was evident. As a result of the biopsy, the three patients were traced, counselled, and offered surgery to remove transplanted tissue. One of the corneal recipients declined, and the other two accepted. All three patients remain well 4 years after transplantation.

This incident sparked a review into our method of selection of tissue donors and raised the question of how many people may be incubating CJD. The basis for removal of the tissue was three previous case reports which indicated that there might be a risk of transmission of the prion in two of the three recipients - that is, following penetrating keratoplasty. However, there have been no cases of transmission from the use of sclera and the evidence from animal studies is inconclusive. This review aims to examine the literature available, with respect to the risk of transmission of prion protein via scleral transplantation and also highlight alternative materials that may eliminate this risk altogether.

\section{EVIDENCE OF RISK}

There have been three reported cases of probable or possible transmission of classic CJD via corneal grafts. The first was in 1974, in the United States, where both the donor and recipient developed CJD proved by brain necropsy. ${ }^{3}$ The second was reported in 1994 by Uchimyama et al. ${ }^{4}$ The patient developed signs indicative of CJD, which was confirmed by postmortem brain necropsy, 15 months after a penetrating keratoplasty, although no information about the donor is known. The third is a case of a 45 year old German woman who developed clinical signs and electrophysiological changes indicative of a "probable" case of CJD, although not confirmed by brain biopsy. She had undergone bilateral corneal grafts, the first at 13 years old and the second at 30 years old. No information is known about the second donor but the first died of pneumonia and post mortem revealed spongiform encephalopathic changes in the brain. ${ }^{6}$ It can only be inferred that the patient had CJD. There are other neuropathological diseases that can exhibit similar changes on biopsy $^{2}$ and the sections are no longer available for examination. Thus, of the three cases of supposed transmission of CJD there is only one that is definite since the others are lacking vital information.

Animal experiments have shown varying results about the risk of transmission. Herzberg transplanted CJD infected corneas onto two capuchin monkeys. They both remained disease free for up to 4 years (the usual incubation time in capuchins). ${ }^{7}$ Manuelidis et al showed the transmission of CJD, if infected corneas were placed into the anterior chamber of uninfected guinea pigs. ${ }^{8}$ However, they did not show transmission of CJD after penetrating keratoplasty. Tateishi injected emulsified CJD infected cornea into the brains of six mice and only one developed characteristic changes after 2.8 years. ${ }^{9}$ Liberski et al have demonstrated the spread of the prion after intraocular inoculation in mice. They showed lesions appearing 18 weeks after inoculation in the superior colliculus and the lateral geniculate body. ${ }^{10}$ The cases demonstrate the inherent infectivity of cornea but not the degree of transmissibility after penetrating keratoplasty. ${ }^{11}$

In a given species the same inoculum injected into multiple animals often produces a range of incubation periods. ${ }^{12}$ The effect of different host genetic loci in mice has been shown to control the length of the incubation of CJD and scrapie. ${ }^{13}$ Incubation periods tend to lengthen with increasing dilutions of brain inocula ${ }^{12}$ and the route of infection also has an effect on infectivity and induction of disease. Longer incubation times are seen with smaller amount of inoculum and intraocular route of infection. ${ }^{8}$ Inocula that produced disease after intracerebral inoculation only irregularly transmitted disease after peripheral inoculation. ${ }^{12}$ However, higher doses can overcome the comparative inefficiency of peripheral routes. At lower doses there was transmission only after extremely long incubation periods or no transmission at all. ${ }^{12}$ The pathological changes in the cerebral cortex after intraocular inoculation 


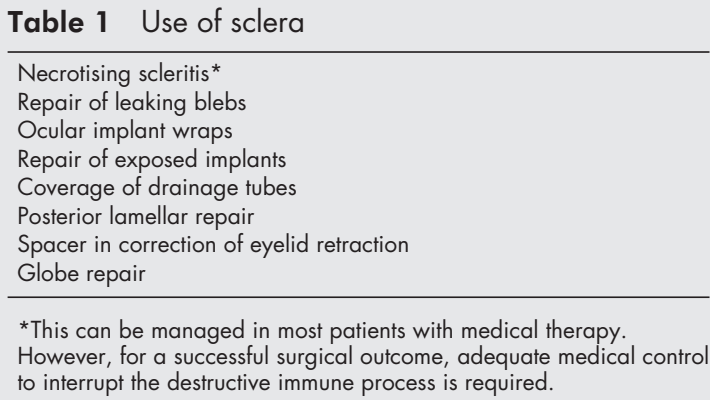

documented by Mauelidis et al were less fulminant and less devastating than changes seen after intracerebral inoculation. $^{8}$

Corneal tissue from scrapie infected hamsters shows a lower concentration of infective prion than brain or retina. ${ }^{14}$ This is consistent with data from the corneal epithelium of hamsters infected with transmissible mink encephalopathy (another spongiform encephalopathy). ${ }^{15}$ Interestingly, no infectivity was demonstrated in the aqueous humour of infected hamsters, ${ }^{15}$ and the authors concluded the infectivity is associated with the numerous nerve fibres in corneal tissue..$^{15}$ However, of concern, titres of prions in corneal tissue, even though less than $5 \%$ of those of retina, were established before the development of clinical signs or histopathological changes of CJD in animals. In the lens levels increased by 10 -fold after the onset of clinical signs. ${ }^{14}$

Even if transplanted scleral tissue does contain minimal levels of prion titres, transmission after a long incubation period is not guaranteed. The susceptibility to CJD also depends on host factors. Homozygosity in the normally polymorphic valine-methionine codon 129 is much more common $(\approx 90 \%+)$ in iatrogenic CJD infected patients than in the normal population $(\approx 38 \%)$, suggesting that a 129 homozygous genotype predisposes to CJD transmission. ${ }^{16}$ However, there are genetic differences between populations-for example, UK and Japanese. ${ }^{17}$ There is also evidence of non-transmissibility. Brown et al showed the failure in transmission of CJD in 9\% of cases from human to primate. ${ }^{12}$ However, the authors felt this was due to experimental transmission failures-that is, if more animals were experimented upon it is possible transmission could occur. ${ }^{12}$

Case reports demonstrate definite human transmission in one case. The animal experiments certainly establish a risk of infectivity in the cornea but at a lower level than neural tissue-for example, brain or retina. However, the risk seems to be associated with corneal nerves harbouring the prion. Scleral nerve density is quite high for such an avascular tissue as witnessed by the pain experienced by patients with scleritis. ${ }^{18}$ However, the density of nerves in the sclera is less than an equivalent portion of cornea. ${ }^{18}$ Hence the relative risk of a piece of scleral tissue should be less than that its corneal equivalent. If transmission occurs at all, it would be expected to be after a long incubation period and be mild in nature.

\section{CURRENT INDICATIONS FOR USE OF SCLERA (TABLE 1) \\ Necrotising scleritis}

Some $5-10 \%$ of cases may require surgical intervention for either diagnosis, to repair scleral defects, to repair globe perforations, or to cover uveal prolapse for threatened perforation in patients with scleromalacia perforans. ${ }^{19}$

\section{Leaking blebs}

Partial thickness ${ }^{20}$ and full thickness ${ }^{21} 22$ scleral patch grafts have been used to treat leaking filtering blebs.

\section{Ocular implants}

Wrap

Homologous sclera, as a wrap for ocular implants, to provide protection of the surrounding orbital soft tissues from mechanical trauma of the implants, is used by many surgeons. ${ }^{23}$

\section{Exposure}

Sclera has also been used in the repair of exposed or extruded orbital implants. ${ }^{24} 25$

\section{Drainage tubes}

Glaucoma drainage devices consisting of a plate and tube are used in the management of complicated adult and paediatric glaucoma. Tube coverage is imperative to prevent conjunctival erosion that may proceed to tube exposure and endophthalmitis. Sclera has been used successfully to cover tubes and hence prevent erosion. ${ }^{26}$

\section{Lid surgery}

Posterior lamellae repair

Sclera has been used as a substitute for tarsus in the reconstruction of the posterior lamellae. ${ }^{27}$

\section{Spacer}

Sclera has also been used in dysthyroid patients as a spacer to correct eyelid retraction. ${ }^{28}$

\section{Repair of globe}

Sclera may be used in trauma cases ${ }^{29}$ or after transscleral wall resection. ${ }^{30}$

\section{METHODS OF SCLERAL USE}

Scleral homografts are the most commonly used form of sclera.

\section{Scleral autograft}

Autoscleral grafting holds several advantages over homografts in that there is minimal postoperative reaction, it has a similar colour to the recipient sclera, it looks cosmetically superior, it is technically easier to obtain the material, and does not expose the recipient to the possibility of transmissible disease from donor material. It has been successfully used as a patch graft in glaucoma tube surgery. ${ }^{31}$ Problems may arise however in cases of posterior thinning of sclera behind the area in which the graft is to be embedded ${ }^{32}$ and also in cases of high myopia and scleritis. ${ }^{31}$

\section{Homologous sclera}

This remains the most common type of material used for grafting. ${ }^{33}$ The scleral may be stored in three ways. ${ }^{34}$

\section{Freezing}

The tissue is stored frozen $\left(-20^{\circ} \mathrm{C}\right)$ in an antibiotic (gentamicin) solution and can be used for up to 3 months from the date of preservation. Thawing should take place at room temperature and once thawed the material should be refrigerated at $2^{\circ}-6^{\circ} \mathrm{C}$ until time of surgery. It should not be refrozen and can be stored for 24 hours.

\section{Glycerine dehydration}

Tissue is preserved in glycerine to dehydrate the sclera and stored at room temperature. It can be used for up to 1 year from date of preservation. At the time of surgery the rehydration of the sclera is achieved by soaking the sclera in balanced salt solution with antibiotics for 15-30 minutes or until normal appearance returns.

\section{Alcohol fixation}

Tissue is preserved in ethanol and stored at room temperature and may be kept viable in this manner for up to 1 year (ensuring the alcohol has not evaporated). Tissue is then washed as 


\begin{tabular}{l} 
Table 2 Alternative materials to sclera \\
\hline Biogenic materials \\
Fascia lata \\
Periosteum \\
Aortic tissue \\
Split thickness dermal grafts \\
Auricular cartilage graft \\
Hard palate mucosa grafting \\
Nasal septum \\
Dura mater \\
Bovine pericardium \\
Human donor pericardium \\
Synthetic materials \\
Poly(tetrafluoroethylene) (PTFE) \\
Polyglactin \\
Poly(ethylene terephthalate) (Dacron) \\
Mersiline \\
Matrices
\end{tabular}

above before use. Alcohol preservation offers some antibacterial activity. ${ }^{35}$ Glutaraldehyde fixation of sclera has been used by dentists in the repair of dental ridge defects. ${ }^{36}$ However, the tissue hardens rendering it less pliable for manipulation.

The use of sclera, whether preserved in alcohol or glycerine, is not without risk of viral transmission even with donor screening. ${ }^{37}$ The serological human immunodeficiency virus (HIV) testing of donors does not guarantee against infection since a potential donor may not test HIV positive for as long as 6 months after infection. ${ }^{38}$ Likewise, there is no serological test for asymptomatic carriers of CJD. Herpes simplex virus has been recovered from sclera stored in glycerine in comparison to ethanol. ${ }^{39}$ Seiff et al showed the presence of HIV virus in the sclera of an HIV positive patient that had been treated with heat, formalin, and alcohol. ${ }^{40}$ The asymptomatic carriers of viral/prion infections may be infective even after the sclera has been preserved by current methods. If transmission of CJD occurs after scleral transplantation, the prion titre would already be established from asymptomatic donors. Hence, current screening may well be pointless and modification of harvested sclera may well be the only answer.

The material may vary in quality and thickness after tissue processing, which may cause ocular surface problems. ${ }^{41}$ It can induce an immunological reaction in the recipient that can result in graft melting, ${ }^{41}$ shrinkage, necrosis, and absorption. Its use in lid surgery can lead to uncertain lid height position because of variable absorption rates, and cyst formation has been documented in the scleral graft. ${ }^{42}$ Its availability does depend on the presence of a tissue bank and may not be available for emergency use.

\section{ALTERNATIVE MATERIALS TO SCLERA (TABLE 2) Biogenic materials Fascia lata}

Fascia lata is commercially available as a gamma radiated strip $^{43}$ (Mile High Transplantation Eye Bank, Denver, CO, USA) or tissue may be removed from the patient's thigh and kept moist and sterile before use. Torchia et al reported the use of such tissue in a patient who had scleromalacia perforans and a previous failed homologous scleral graft. ${ }^{44}$ Ten months later the graft remained intact even though no postoperative immunosuppression was used. Blum et al used homologous fascia lata ${ }^{45}$ in the same clinical setting and described a similar result. The advantages of such a material are its readily availability, autogenicity, and durability. Fascia lata patch grafts have also been used to cover glaucoma tubes with success $^{46}$ and to repair overfiltering blebs. ${ }^{43}$

\section{Periosteum}

Koenig et al reported the use of this material to reinforce scleral thinning, perforation, and corneoscleral wound dehiscence in patients with necrotising scleritis and peripheral ulcerative keratitis associated with rheumatoid arthritis. ${ }^{47} 48$ Previous attempts with homologous sclera grafts were unsuccessful because the donor tissue did not vascularise and became necrotic and sloughed off. The advantage of this material is its strength and the ease with which the tissue vascularises owing to its bilayer structure. It is also not susceptible to immunological graft rejection. Obtaining the periosteum needs to be undertaken under general anaesthesia. Once positioned the graft can be covered by conjunctiva. ${ }^{47} 48$

\section{Aortic tissue}

This material has been used to reinforce thinned sclera. It is not used in its entirety but the adventitia and the intima are removed leaving only the elastic layer. ${ }^{49}$ The advantage of such material is its elasticity, strength, immunological inactivity, and ease of repair. A patient who received the material remained free from complications for 5 years. However, availability of material will limit its use.

\section{Split thickness dermal grafts}

Dermal graft obtained from the thigh can be used to repair scleral and corneal defects ${ }^{50}$ as well as being an alternative to sclera for covering extruding orbital implants. The advantages are that it is autogenous, non-antigenic, can survive on avascular surfaces, and can self epithelialise. The latter allows the graft to be used in cases in which the conjunctiva may be sparse since graft covering is not needed. The main complication reported is post-surgical thinning.

\section{Auricular cartilage graft}

Auricular cartilage has been used as an alternative to scleral homografts as an additional posterior lamellar support or for posterior lamellar augmentation. ${ }^{51}{ }^{52}$ It is relatively easily obtainable, under local anaesthesia, removing the cartilage from the posterior aspect of the pinna. However, it is thicker than tarsus and splitting the graft material may be advantageous in order to improve lid contour and shape postoperatively. ${ }^{53}$ Alternatively, auricular conchal cartilage may be used which is more elastic, softer, and more pliable. ${ }^{54}$ Auricular cartilage lacks an epithelial surface but most cases do eventually re-epithelialise from adjacent conjunctiva, but if not, may require removal. ${ }^{55}$

\section{Hard palate mucosa grafting}

The hard palate has been a useful source as an alternative to sclera for stiffening or as a spacer to lengthen the posterior lamella. ${ }^{56}$ It easily approximates to the contour, thickness, and stiffness of tarsus, ${ }^{36}$ and is easily obtainable and well tolerated. It has an epithelial lined surface relinquishing the need for a conjunctival covering.

\section{Nasal septum}

As with auricular cartilage and hard palate, the nasal septum can be used as an alternative to sclera for posterior lamellae reconstruction. ${ }^{57}$ Avoidance of septal perforation after removal of the graft will depend on the maintenance of an intact nasal mucosa on the contralateral side. As with hard palate, there is an inherent epithelial lined surface offering advantage in conjunctival sparing procedures. The graft, once taken, will need to be thinned, to imitate tarsus before use..$^{57}$

\section{Dura mater}

Dura mater has been used successfully for patch grafting of filtration tubes to prevent conjunctival erosion.$^{41}$ It is available as commercially prepared treated and gamma irradiated (Tutoplast Dura) sheets. Manipulation of the material may be done easily before rehydration. The treatment stage is to eliminate the transmission of $\mathrm{HIV}^{58}$ and $\mathrm{CJD},{ }^{59}$ the risk of CJD propagation is well established by the use of infected dura. ${ }^{60}$ 
Treatment involves processing with $1 \mathrm{M} \mathrm{NaOH}$ for 1 hour. Some authors feel that complete inactivation may not be achieved and that the incubation period is merely extended. ${ }^{61}$ However, there have been no cases of CJD transmission caused by dura mater since this treatment stage was added ${ }^{60}$

\section{Bovine pericardium}

This has been used as a wrap for orbital implants. ${ }^{62}$ Its advantages are that it is thin, supple, pliable, and has excellent suture retention and strength. The material may be obtained in a manufactured form (Periguard; Bio-Vascular, Inc, St Paul, MN, USA) that renders the material antigenically inert and adds to its strength and longevity. It has been shown to be well tolerated and to elicit minimal inflammation ${ }^{62}$ in animal studies. The same authors have also described the use of bovine pericardium as a lower lid spacer graft as an alternative to homologous sclera ${ }^{63}$ in rabbits. Again clinically they found no difference in lids that had had the bovine pericardium from those with sclera. Histologically there was a degree of inflammation noted with the former material. However, when used as a wrap for hydroxyapatite orbital implants in patients the results showed a much higher incidence of wound dehiscence compared to the sclera control group. ${ }^{64}$

The use of bovine pericardium may be applicable to products purchased from the United States since BSE has never been detected in US cattle. Even though pericardial tissue has not been shown to be associated with $\mathrm{BSE}^{65}$ we feel it would be used with scepticism in the United Kingdom.

\section{Human donor pericardium}

Pericardial patch grafts have been used to cover glaucoma drainage devices ${ }^{66}$ and also to cover exposed scleral buckles. ${ }^{67} \mathrm{It}$ is available commercially (Tutoplast) in a sterilised irradiated form that also leaves the graft cells without antigenic stimuli. The material can then be manipulated as required. However, diffuse graft thinning of the pericardial patch leading to tube exposure and conjunctival erosion has been noted in several cases. $^{68}$

\section{Synthetic materials}

\section{Poly(tetrafluoroethylene) (PTFE)}

PTFE has been widely used in vascular surgery as a patch graft since the 1970s. The material is made up of nodules of PTFE connected by fibrils that allow the growth of connective tissue through the pores and hence allow vascularisation. It is inert and hydrophobic, invoking minimal inflammatory reaction. Successful use of the material has been described in the reinforcement of sclera in rabbits ${ }^{69}$ as well as a spacer in the correction of lower eyelid retraction. ${ }^{70}$ In repair of scleral defects following necrotising scleritis in humans, Huang et al reported poor epithelial and fibrous tissue ingrowth of the PTFE graft if used without conjunctival covering. ${ }^{71}$ The graft supports epithelial and endothelial overgrowth, but these are slow processes and limited to the extent they occur. ${ }^{72}$ Interestingly, these authors noted poor adhesion between graft and surrounding tissue but also neovascularisation of the tissue surrounding the graft. ${ }^{71}$ The PTFE graft must have adequate conjunctival covering and is well tolerated under the conjunctiva. $^{73}$ A $2 \mathrm{~mm}$ thick graft is available, which can be used to provide support for the lower lid. ${ }^{70}$

\section{Polyglactin}

Polyglactin is an undyed braided Vicryl mesh that has been used as an alternative to sclera as a wrap for orbital implants. ${ }^{74}$ As with sclera the extraocular muscles may be directly sutured to the Vicryl mesh to aid motility. The material is identical in composition to polyglactin synthetic absorbable suture, which has been found to be inert, non-antigenic, and non-pyrogenic. ${ }^{75}$ The mesh absorbs by hydrolytic decomposition with minimal tissue reaction over
45-60 days. During this time fibrovascular ingrowth can take place over the entire surface of the implant because of the multiple holes within the mesh.

\section{Poly(ethylene) terephthalate (Dacron/terylene)}

Dacron is a homopolymer of the thermoplastic type. It has a regular linear structure and is formed from the reaction of ethylene glycol with terephthalic acid. ${ }^{81}$ It possesses good strength, rigidity, and is hard and resistant. It is widely used in vascular surgery as an arterial prosthesis, and is well tolerated with minimal tissue reaction. Owing to its resistance to hydrolysis at normal temperatures it can be expected to remain in vivo forever ${ }^{82}$ and hence work was initially done for its use as suture material. ${ }^{81}$ It has also been used for scleral wall reinforcement where it has been shown to be well tolerated in rabbits. ${ }^{79}$ The material incorporated overlying and underlying host fibrovascular tissue and was thoroughly fixated. The results would indicate the possibility of use as a patch graft indefinitely.

\section{Mersilene}

Mersilene is an interwoven polyester fibre mesh that has been used successfully in ptosis surgery as a sling ${ }^{76}$ and in cases of eyelid retraction. ${ }^{77}$ It has also been used as a wrap for orbital implants. ${ }^{78}$ The advantage is that it is easily prepared and can be used from the shelf. The postoperative inflammation is minimal. However, as with all trauma cases care must be taken with all non-autogenous material used as a wrap by covering postoperatively with antibiotics. Mersilene has been used for scleral reinforcement. ${ }^{79}{ }^{80}$ The material was well tolerated and showed fibrovascular ingrowth indicating the possible use of this material as a substitute for sclera.

\section{Matrices}

Resorbable matrices may have applications in the aid of ocular surface regeneration. ${ }^{83}$ The limitation of solid organ constructs to their vascular supply ${ }^{84}$ suggests the possibility of cornea and sclera as potential products of tissue engineered organ replacement. However, collagen used for matrices comes from animal sources hence not eliminating the risk of prion infection, but a recombinant source would eliminate this risk. ${ }^{83} \mathrm{~A}$ synthetic matrix would be an adequate alternative and could also provide additional integral benefits.

\section{CONCLUSIONS}

CJD is a disease with a single pathogenesis expressed with kaleidoscopic variety. ${ }^{12}$ Several factors, as detailed previously, will determine the infectivity of scleral tissue, if contaminated, when implanted in to a patient. ${ }^{85}$

Protagonists of the use of sclera would argue that the level of infectious prion titre in sclera would be small and the quantity of sclera used in many cases would also be small. The risks of transmission may be further reduced by predonor screening and by post-harvesting treatment with $1 \mathrm{M} \mathrm{NaOH}^{59}$ or $4 \mathrm{M}$ guanidine thiocyanate. ${ }^{86}$ Even though other authors have not shown complete inactivation of prion protein with 1 $\mathrm{M} \mathrm{NaOH},{ }^{61}$ the key to post-treatment levels of infectivity is the level of prion titre in the pretreatment tissue. ${ }^{87}$ The studies were all done with brain homogenates and evidence suggests corneal tissue contains prion titres at lower concentration than brain, and the same can be assumed of sclera. Hence, the effect of chemicals on CJD inactivation would be more pronounced on cornea/scleral tissue.

Opponents of the use of sclera would point out that transmission has occurred previously after patient exposure to low doses of prions. Patients who received hormones from cadaveric pituitary glands were exposed to very low doses subcutaneously of the infectious agent. They developed CJD characterised by very long incubation times with marked cerebellar symptoms similar to kuru, suggesting an exogenous source of 
infection ( $c f$ familial or sporadic) ${ }^{88}$ In addition, absolute inactivation of CJD cannot be guaranteed by current decontamination methods ${ }^{86}$ but a reduction in prion titres may be seen, which may reduce the concentration of the prion to untransmissible levels. $^{87}$

CJD remains rare, the number of cases of sporadic CJD is stable. However, vCJD has caused concern since the scale of the problem is as yet unknown, with possible projections of future cases ranging from thousands to hundreds of thousands in the coming decades. The virulence of the prion in vCJD is of concern. In experimental transmission studies "acquired" agents were shown to be more virulent than in genetically determined or spontaneously occurring disease. ${ }^{12}$ The prion itself has already survived the harsh rendering process used in the production of scrapie infected feed, self selecting a strain to become a more resistant agent causing BSE. ${ }^{86}$ The current methods for decontamination may well not apply to vCJD.

With the use of a small amount of sclera the prion titre level may well remain below transmissible levels. However, in cases where multiple graft material may be used-for example, paediatric patients undergoing glaucoma drainage tube insertion and then further penetrating keratoplasty, the risk of possible exposure of patients to higher titres of prions is present. In young patients there will be ample time for incubation. Even with small amounts of sclera, infected by a virulent strain of prion in a genetically susceptible host, transmission could occur.

The use of sclera in ophthalmology has increased over the past decade. European eye banks studied from 1991 to 1995, on average issued sclera 24 times per annum over the 5 year period. ${ }^{89}$ However, more recent data from UK Transplant showed 75 sclera transplants for a 6 month period to the end of 1999 and 172 transplants for the year 2000. Patients as well as surgeons, require reassurance of the safety of using homologous scleral tissue. Further research may provide that assurance but until then, where possible, the use of alternative materials should be carefully considered.

\section{ACKNOWLEDGEMENT}

The authors would like to thank Phil Pocock, information executive, UK Transplant for providing information about the number of scleral transplants performed.

\section{Authors' affiliations}

J S Mehta, W A Franks, Moorfields Eye Hospital, City Road, London ECIV 2PD, UK

\section{REFERENCES}

1 Christie B. High vCJD rates in Scotland could be due to poor diet. BM 2001;323:590-1.

2 Hogan RN, Brown P, Heck E, et al. Risk of prion disease transmission from ocular donor tissue transplantation. Cornea 1999;18:2-11.

3 Duffy $\mathbf{P}$, Wolf, Collins $G$, et al. Possible person-to-person transmission of Creutzfeldt-Jakob disease. N Engl J Med 1974;290:692-3.

4 Uchiyama K, Ishida C, Yago S, et al. An autopsy case of Creutzfeldt-Jakob disease associated with corneal transplantation. Dementia 1994;8:466-73.

5 World Health Organization. Global surveillance, diagnosis and therapy of human transmissible spongiform encephalopathies: report of a WHO consultation. WHO/EMC/ZDI/98.9. Geneva: WHO, 1998.

6 Heckmann JG, Lang CJG, Petruch F, et al. Transmission of Creutzfeldt-Jakob disease via a corneal transplant. J Neurol Neurosurg Psychiatry 1997;63:388-90.

7 Herzberg L. Creutzfeldt-Jakob disease and corneal grafts. Med J Aust $1979 ; 1: 248$

8 Manuelidis EE, Angelo JN, Gorgacz EJ, et al. Experimental Creutzfeldt-Jakob disease transmitted via the eye with infected cornea. $\mathrm{N}$ Engl J Med 1977;296:1334-6.

9 Tateishi J. Transmission of Creutzfeldt-Jakob disease from human blood and urine into mice. Lancet 1985;2:1074

10 Liberski PP, Yanagihara R, Gibs CJ, et al. Spread of Creutzfeldt-Jakob disease virus along visual pathways after intraocular inoculation. Arch Virol 1990;111:141-7.

11 Hogan RN, Cavanagh HD. Transplantation of corneal tissue from donors with disease of the central nervous system. Cornea 1995;14:547-53.
12 Brown P, Gibbs DJ, Rodgera-Johnson P, et al. Human spongiform encephalopathy: the National Institutes of Health series of 300 cases of experimental transmitted disease. Ann Neurol 1994;35:513-29.

13 Kingsbury DT, Kasper KC, Stites DP, et al. Genetic control of scrapie and Creutzfeldt-Jakob disease in mice. J Immunol 1983;131:491-6.

14 Hogan RN, Bowman KA, Baringer JR, et al. Replication of scrapie prions in hamster eyes precedes retinal degeneration. Ophthalmic Res 1986;18:230-5

15 Marsh RF, Hanson RP. Transmissible mink encephalopathy: infectivity of corneal epithelium. Science 1975;187:656.

16 Collinge J, Palmer MS, Dryden AJ. Genetic predisposition to iatrogenic Creutzfeldt-Jakob disease. Lancet 1991;337:1441-2.

17 Doh-ura K, Kitamoto T, Sasaki Y, et al. CJD discrepancy. Nature $1991 ; 353: 801-2$

18 Watson PG, Hazelman BL. The sclera and systemic disorders. Philadelphia: WB Saunders, 1976.

19 Foster CS, Sainz de la Maza M. The sclera. New York: Springer-Verlag, 1994:95-170, 299-307.

20 Clune MJ, Shin DH, Olivier MMG, et al. Partial thickness scleral patch graft in revision of trabeculectomy. Am J Ophthalmol 1993;115:818-20.

21 Melamed S, Ashkenazi I, Belscher III DC, et al. Donor scleral graft patching for persistent filtering bleb leak. Ophthalmic Surg 1991;22:164-5

22 Kosmin AS, Wishart PK. A full-thickness scleral graft for the surgical management of a late filtration bleb leak. Ophthalmic Surg Lasers 1997;28:461-8.

23 Rubin PAD, Popham JK, Bilyk JR, et al. Comparison of fibrovascular ingrowth into hydroxyapatite and porous polyethylene orbital implants. Ophthalmic Plast Reconstr Surg 1994; 10:96-103.

24 Helverston EM. Human bank scleral patch. For repair of exposed or extruded orbital implants. Arch Ophthalmol 1969;82:83.

25 Soll DB. The use of sclera in surgical management of extruding implants. Trans Am Acad Ophthalmol Otolaryngol 1978;85:863-8.

26 Freedman J. Scleral patch grafts with Molteno setons. Ophthalmic Surg $1987 ; 18: 532-4$

27 Flanagan JC. Eye Bank sclera in oculoplastic surgery. Ophthalmic Surg 1974:5:45-53.

28 Doxanas MT, Dryden RM. The use of sclera in the treatment of dysthyroid eyelid retraction. Ophthalmology 1981;88:887-94.

29 Rodriguez-Ares MT, Tourino R, Capeans C, et al. Repair of scleral perforation with preserved scleral and amniotic membrane in Marfan's Syndrome. Ophthalmic Surg Lasers 1999;30:485-7.

30 Naumann GO, Rummelt V. Block excision of tumours of the anterior uvea. Report of 68 consecutive patients. Ophthalmology 1996; 12:2017-27.

31 Aslanides IM, Spaeth GL, Schmidt CM, et al. Autologous patch graft in tube shunt surgery. J Glaucoma 1999;8:306-9.

32 Gopal L, Badrinath SS. Autoscleral flap grafting: a technique of scleral repair. Ophthalmic Surg 1995;26:44-8.

33 Johnson WA, Henderson JW, Parkhill MD, et al. Transplantation of homografts of sclera: an experimental study. Am J Ophthalmol 1962;54:1019-30

34 Nguyen QD, Foster CS. Scleral patch graft in the management of necrotizing scleritis. Int Ophthalmol Clin 1999;39:109-31.

35 Dailey JR, Rosenwasser GOD. Viability of bacteria in glycerin and ethanol preserved sclera. J Refract Corneal Surg 1994;10:38-40.

36 Spatzner M, Deporter DA. Preprosthetic alveolar ridge correction using glutaraldehyde cross-linked, lyophilised scleral allografts. Compendium 1990;11:176.

37 Lusky M, Weinreb RN. Preservation of scleral grafts to avoid HIV infection. J Glaucoma 1992;1:221

38 Horsburgh CR, Ou CY, Jason J, et al. Duration of human immunodeficiency virus infection before detection of antibody. Lancet 1989;2:637

39 Rosenwasser GOD, Jones RL, Greene WH. Recovery of herpes simplex virus from preserved sclera. Invest Ophthalmol Vis Sci 1993:34:1494.

40 Seiff SR, Chang JS, Hurt MH, et al. Polymerase chain reaction identification of human immunodeficiency virus-1 in preserved human sclera. Am J Ophthalmol 1994;1 18:528-30.

41 Brandt JD. Patch grafts of dehydrated cadaveric dura mater for tube shunt surgery. Arch Ophthalmol 1993;111:1436-9.

42 Harvey JT, Anderson RL. The Aponeurotic approach to eyelid retraction. Ophthalmology 1981;88:513-24.

43 Hughes BA, Shin DH, Birt CM. Use of fascia lata in revision of filtration surgery. J Glaucoma 1996;5:207-9.

44 Torchia RT, Dunn RE. Fascia lata grafting in scleromalacia perforans. Am J Ophthalmol 1968;66:705-9.

45 Blum FG, Salamoun SG. Scleromalacia perforans-a useful surgica modification in fascia lata or scleral grafting. Arch Ophthalmol 1963;69:43-5.

46 Tanii TM, Lundy DC, Minckler DS, et al. Fascia lata patch graft in glaucoma tube surgery. Ophthalmology 1996;103:1309-12

47 Koenig SB. The treatment of necrotizing scleritis with an autologenous periosteal graft. Ophthalmic Surg 1983;14:1029-32.

48 Koenig SB, Sanitato JJ, Kaufman HE. Longterm follow-up study of scleroplasty using autogenous periosteum. Cornea 1990;9:139-43.

49 Merz EH. Scleral reinforcement. Am J Ophthalmol 1964;54:1019-30.

50 Mauriello JA Jr, Pokorny K. Use of split-thickness dermal grafts to repair corneal and scleral defects - a study of 10 patients. Br J Ophthalmol 1993;77:327-31.

51 Baylis HI, Rosen N, Neuhaus RW. Obtaining auricular cartilage for reconstructive surgery. Am J Ophthalmol 1982;93:709. 
52 Yaqub A, Leatherbarrow B. The use of autogenous auricular cartilage in the management of upper eyelid entropion. Eye 1997;1 1:801-5.

53 Smith B, Lisman RD. Preparation of split thickness auricular cartilage for use in ophthalmic plastic surgery. Ophthalmic Surg 1982;13:1018-23.

54 Marks MW, Argenta LC, Friedman RJ, et al. Conchal cartilage and composite grafts for correction of lower lid retraction. Plastic Reconstruct Surg 1989;83:629-35

55 Kersten RC, Kulwin DR, Levartovsky S, et al. Management of lower-lid retraction with hard-palate mucosa grafting. Arch Ophthalmol 1990; 108:1339-43

56 Bartley GB, Kay PP. Posterior lamellar eyelid reconstruction with a hard palate mucosal graft. Am J Ophthalmol 1989;107:609-12.

57 Millard RD. Eyelid repairs with a chondromucosal graft. Plastic Reconstruct Surg 1962;30:267-72.

58 Resnick L, Veren K, Salahuddin SZ, et al. Stability and inactivation of HTLV-1 11 /LAV under clinical and laboratory environments. JAMA 1986;255:1887-91

59 Brown P, Rohwer RG, Gajdusek DC. Sodium hydroxide decontamination of Creutzfeldt-Jakob disease virus. N Engl J Med 1984;310:727.

60 Yamada S, Aiba T, Endo Y, et al. Creutzfeldt-Jakob disease transmitted by a cadaveric dura mater graft. Neurosurgery 1994;34:740-3.

61 Tamai Y, Taguchi F, Miura S. Inactivation of the Creutzfeldt-Jakob disease agent. Ann Neurol 1988:24;466-7.

62 DeBacker CM, Dutton JJ, Proia AD, et al. Bovine pericardium versus homolgous sclera as wrapping materials for hydroxyapatite ocular implants: an animal study. Ophthalmic Plastic Reconstr Surg $1999 ; 15: 312-16$.

63 DeBacker CM, Dutton JJ, Proia AD, et al. A comparative study of bovine pericardium (periguard) and homologous sclera as lower eyelid spacer graft analogs in new zealand white rabbits. Ophthalmic Plast Reconstr Surg 1999; 16:155-61

64 Char DH. Early wound dehiscence with use of hydroxyapatite orbital implant covered with calf pericardium. Br J Ophthalmol 2001;85:627-8.

65 Wells GAH, Hawkins SAC, Green RB, et al. Preliminary observations on the pathogenesis of experimental bovine spongiform encephalopathy (BSE): an update. Vet Rec 1998;142:103-6.

66 Raviv T, Greenfield DS, Liebmann JM, et al. Pericardial patch grafts in glaucoma implant surgery. J Glaucoma 1998;7:27-32.

67 Weissgold DJ, Millay RH, Bochow TA. Rescue of exposed scleral buckles with cadaveric pericardial patch grafts. Ophthalmology 2001; 108:753-8.

68 Lama PJ, Fechtner RD, Newark NJ. Tube erosion following insertion of a glaucoma drainage device with a pericardial patch graft. Arch Ophthalmol 1999;117:1243-4.

69 Öhrström A Stenkula S, Berglin L, et al. Scleral reinforcement by ateflon graft and a tissue adhesive. Acta Ophthalmol (Copenh) 1988;66:643-6.
70 Karesh JW, Fabrega MA, Rodrigues MM, et al. Polytetrafluoroethylene as an interpositional graft material for the correction of lower eyelid retraction. Ophthalmology 1989;96:419-23.

71 Huang WJ, Hu FR, Chang SW. Clinicopathologic study of Gore-Tex patch graft in corneascleral surgery. Cornea 1994;13:82-6.

72 Karesh JW. Polytetrafluoroethylene as a graft material in ophthalmic plastic and reconstructive surgery: an experiment and clinical study. Ophthalmic Plast Reconstr Surg 1987;3:179-85

73 Tawakol ME, Peyman GA, Lui KR, et al. Gore-Tex soft tissue bands as scleral explants in rabbits: a preliminary histology study. Ophthalmic Surg 1989;20:199-201.

74 Jordan DR, Allen LH, Ells A et al. The use of vicryl mesh (polyglactin 910) for implantation of hydroxyapatite orbital implants. Ophthalmic Plast Reconstr Surg 1999;1 1:95-9.

75 Ethicon. Product monograph description. Somerville, NJ: Ethicon Inc, a Johnson \& Johnson Company, 0886-0151.

76 Downes RN, Collin JRO. The mersilene mesh sling: a new concept in ptosis surgery. Br J Ophthalmol 1989;73:498-501

77 Downes RN, Jordan K. The surgical management of dysthyroid related eyelid retraction using mersilene mesh. Eye 1989;3:385-90.

78 Hughes JD, Downes RN, Kemp E. The mersilene covered intraorbital implant. Eye 1992;6:484-6.

79 Whitmore WG, Harrison W, Curtin BJ. Scleral reinforcement in rabbits using synthetic graft materials. Ophthalmic Surg 1990;21:327-30.

80 Tarutta EP, Andreeva LD, Markosian GA et al. Reinforcement of the sclera with new types of synthetic materials in progressive myopia. Vestn Oftalmol 1999;115:8-10.

81 Jaffe NS. Polyethylene terephthalate (Dacron) in intraocular surgery. Ophthalmology 1981;88:955-8.

82 Narat JK, Cangelosi JP, Belmonte JV. Evaluation of Dacron suture materials for general surgery. Surg Forum 1956;7:176-8.

83 Allan B. Closer to nature: new biomaterials and tissue engineering in ophthalmology. Br J Ophthalmol 1999;83:1235-40.

84 Sittinger $\mathrm{M}$, Bujia J, Rotter $\mathrm{N}$, et al. Tissue engineering and autologous transplant formation: practical approaches with resorbable biomaterials and new culture techniques. Biomaterials 1996;17:237-42.

85 Lueck CJ, Mcllwaine GG, Zeidler M. Creutzfeldt-Jakob disease and the eye. Background and patient management. Eye 2000;14:263-90.

86 Manuelidis L. Decontamination of Creutzfeldt-Jakob disease and other transmissible agents. J NeuroVirol 1997:3:62-5.

87 Brown P, Gibbs CJ, Amyx DVM, et al. Chemical disinfection of Creutzfeldt-Jakob disease virus. N Engl J Med 1982;306:1279-82.

88 Brown P, Preece MA, Will RG. 'Friendly fire' in medicine: hormones, homografts, and Creutzfeldt-Jakob disease Lancet 1992:340:24-7.

89 Maas-Reijs J, Pels E, Tullo AB. Eye banking in Europe 1991-5. Acta Ophthalmol. Scand 1997;75:541-3. 